\title{
Social Capital as a Moderator for Caregivers' Psychological Distress: A Dynamic Panel Data Model Analysis in Japan
}

\author{
Takashi Oshio ( $\square$ oshio@ier.hit-u.ac.jp ) \\ Hitotsubashi University \\ Kemmyo Sugiyama \\ Tohoku University Graduate School of Dentistry
}

\section{Research Article}

Keywords: Caregiving, dynamic panel data model, moderating effect, psychological distress

Posted Date: July 13th, 2021

DOI: https://doi.org/10.21203/rs.3.rs-598194/v1

License: (1) This work is licensed under a Creative Commons Attribution 4.0 International License. Read Full License 


\section{Abstract}

Background: The adverse impact of caregiving on caregivers' mental health and the positive impact of social capital (SC) on health are both well understood. This study examined the moderating effect of SC on the association between family caregiving and caregivers' psychological distress (PD).

Methods: We used longitudinal data from 27,869 individuals born between 1946 and 1955. The data were collected from a 14-wave nationwide longitudinal survey conducted from 2005 to 2018 . We estimated dynamic panel data (DPD) models, which could control for an individual's time-invariant attributes in a dynamic framework. We did this to examine how SC moderated the association between informal caregiving and a caregiver's PD (defined by a Kessler score of 13 or higher). We also examined how the results varied over time, as the caregiver's age advanced.

Results: Of the respondents aged $50-73$ years, $12.5 \%$ of women and $8.4 \%$ of men provided care to their older parents or spouses. The DPD model results showed that the onset of caregiving increased the probability of PD $(M 3.4 \%)$ by $2.1 \%$ (95\% confidence interval [CI]: $1.6 \%-2.7 \%)$ and $1.1 \%(95 \% \mathrm{Cl}: 0.5 \%-1.6 \%)$ for women and men, respectively. SC moderated the association between caregiving and a caregiver's PD by $53.4 \%$ (95\%: $30.4 \%-76.4 \%)$ and $84.9 \%$ (95\% Cl: $62.0 \%-107.8 \%)$ for women and men, respectively. We also observed that the moderating effect of SC on a caregiver's PD increased as the caregiver's age advanced in both women and men, preventing a deterioration in the psychological impact of caregiving.

Conclusions: The results underscore the moderating effect of SC on the association between caregiving and PD. This suggests the need to keep family caregivers from being socially isolated, especially as they get older.

\section{Background}

Extended life expectancy along with a consistently less number of multi-child families in advanced countries has increased the likelihood that middle-aged or older adults provide informal care to their parents and/or spouses. It is widely understood that informal caregiving is predictive of a deterioration of a caregiver's mental health. Several studies show that subjective care burden is associated with negative health outcomes, including depression, anxiety, and poor self-rated health [1-7]. Therefore, reducing informal caregivers' psychological burdens is a challenge and necessity in an aging society. This is true even after the introduction of public long-term care schemes.

It should be noted, however, that the impact of informal caregiving on caregivers' mental health may change with advancing age. Older caregivers are more likely to face limited financial resources, poorer health conditions (including a higher risk of being frail or disabled), and changes in major life events (such as retirement, child independence, divorce, and separation from family members). All of these factors are likely to place additional psychological pressure on older caregivers. In this regard, there is rising importance surrounding "elderly-for-elderly care," or, informal care given by the elderly to the elderly [8-10]. The latest survey conducted by the Japanese Ministry of Health, Labour, and Welfare (MHLW) showed that the proportion of caregivers aged 65 years or above who are caring for their family members aged 65 or above has increased from $40.6 \%$ in 2001 to $59.7 \%$ in 2019 [11].

Social capital (SC) is a potential factor in mitigating the impact of informal caregiving in caregivers [12]. Increasing attention has been paid to SC's health-promoting role. SC is considered an essential device to achieve effective social and/or economic outcomes, which include better health outcomes for caregivers [13-15]. In particular, studies have shown that individual health outcomes are strongly associated with individual-level SC, especially among older individuals (e.g., [16-19]).

However, the role played by SCs in the association between informal caregiving and caregivers' mental health is yet to be effectively studied. A notable exception is Mohanty et al. (2019)'s cross-sectional analysis [20], which showed that SC had a favorable impact on both the mental and general health of caregivers and non-caregivers. This study did demonstrate that SC was more beneficial for caregivers than non-caregivers. However, a cross-sectional study cannot fully control for endogeneity or simultaneity biases related to an individual's unobserved attributes. Moreover, the moderating effect of SC may differ between younger and older caregivers, which is another issue that needs to be researched.

In this study, we examined the moderating effect of SC on the association between caregiving to older parents/spouse and a caregiver's PD using a 14-wave nationwide longitudinal survey in Japan. This study had two features that were expected to provide new insights into the psychological relevance of caregiving for middle-aged or older adults. First, we employed dynamic panel data (DPD) models [21], which allowed us to control for an individual's time-invariant attributes in a dynamic framework of the longitudinal data setting. This analytical strategy helped us obtain less biased estimation results than a cross-sectional study could have.

Second, we compared the association between caregiving and PD with the moderating effect of SC on this association between younger and older age groups. We did this to consider the relevance of our data for "elderly for elderly" care. To this end, we estimated the same DPD model for the 10-year age range group by sliding the age range by one year from 55-64 years to 63-72 years, and compared the results across nine age groups. 


\section{Methods \\ Study sample}

We used data obtained from a nationwide 14-wave panel survey, entitled "The Longitudinal Survey of Middle-Aged and Older Adults," conducted by the Japanese Ministry of Health, Labour and Welfare (MHLW) each year from 2005 to 2018. Japan's Statistics Law required the survey to be reviewed from statistical, legal, ethical, and other viewpoints.

The survey began with a cohort of people who were 50-59 years of age (born between 1946 and 1955) for the first wave. A total of 34,240 individuals responded (response rate: $83.8 \%$ ). The second to fourteenth waves of the survey were conducted each year from 2006 to 2018 . By the fourteenth wave, 20,677 individuals remained. For descriptive analysis, we used pooled cross-sectional data of 325,487 observations of 30,243 individuals (15,588 women and 14,655 men), after excluding missing key variables. For regression analysis, we focused on (unbalanced) longitudinal data of 235,163 observations from 27,869 individuals (14,377 women and 13,492 men), who provided no care to any of their older family members in the year prior to each survey.

\section{Materials}

\section{Caregiving}

The survey asked individuals if and to whom they were providing informal care. We constructed a binary variable of caregiving by allocating one to the individuals who answered that they were caring for at least one of their parents, parents-in-law, or spouse - regardless of coresidence with them - and zero to others.

\section{Psychological distress (PD)}

We measured PD using Kessler 6 (K6) scores [22, 23]. Earlier studies have confirmed the reliability and validity of this score in the psychological analyses of Japanese people [24, 25]. The survey asked participants to answer a six-item psychological distress questionnaire. The questionnaire included: "During the past 30 days, how often did you feel a) nervous, b) hopeless, c) restless or fidgety, d) so depressed that nothing could cheer you up, e) that everything was an effort, and f) worthless?" These were rated on a 5 -point scale $(0=$ none of the time to $4=$ all of the time). Furthermore, the sum of the reported scores (range: 0-24) was calculated and defined as the K6 score. The Cronbach's alpha for the entire study sample was 0.897 . $K 6$ scores $\geq 13$ indicates PD in a Japanese sample, as validated by previous studies $[23,25]$. We constructed a binary variable of PD by allocating one to $\mathrm{K} 6$ scores $\geq 13$ and zero to those $<13$.

\section{Social capital (SC)}

To construct the SC variable, we utilized answers to the question about participation in social activities, as used by previous studies in Japan (e.g., [16]). The survey asked respondents whether they participated in six types of social activities: (1) hobby or entertainment; (2) sports or physical exercises; (3) community activities; (4) childcare support, or educational or cultural activities; (5) support for the elderly; and (6) others (multiple answers permitted). If respondents answered yes, they were asked to indicate with whom they participated in each activity by choosing: (1) alone, (2) family members or friends, (3) workplace colleagues, (4) members in a neighborhood association, or (5) members in a non-profit organization or public-service corporation. Multiple answers were permitted). We considered that respondents who chose at least one item from (2)-(5) in at least one of the six social activities (1)-(6) had SC.

\section{Covariates}

For individual-level covariates, we considered marital status, employment status, household spending, current tobacco smoking, educational attainment, and age at baseline (in 2005). We constructed binary variables for having a spouse, having a paid job, and current smoking by allocating one to those who answered that they were married, have a paying job, and currently smoke, respectively, and zero to those who answered "no" to those questions. Regarding household spending as a proxy for household income, we divided the reported monthly household spending by the square root of the number of household members to adjust it by household size [26]. We categorized it into quartiles and constructed binary variables for each quartile. To the respondents who did not answer for household spending, we allocated a binary variable for unanswered. Regarding educational attainment, we constructed five binary variables for graduating from junior high school, high school, junior college, college or above, and other. We also constructed binary variables for each age at baseline. We further included binary variables for each survey year to control for survey-year-specific factors. In the DPD regression, ages at baseline and educational attainment were automatically removed because they were time-invariant.

\section{Statistical analysis}

We began by using descriptive analysis to describe unadjusted associations across caregiving, SC, and PD by comparing the prevalence of PD across four types of respondents: non-caregivers with SC, non-caregivers with no SC, caregivers with SC, and caregivers with no SC. We did so 
using pooled cross-sectional data.

For regression analysis, we limited the study sample to those who provided no care in the previous year and estimated a DPD model [21] in the form of a linear probability model (LPM) $[27,28]$, which linearly predicts the probability of individual is PD in wave $t$ as:

$P D_{i t}=\beta_{0}+\beta_{1}$ Caregiving $_{i t}+\beta_{2} \mathrm{SC}_{i t}+\beta_{3}$ Caregiving $_{i t} \times \mathrm{SC}_{i t}+\beta_{4} P D_{i t-1}+($ covariates $)+u_{i}+\varepsilon_{i t}$

where $u_{i}$ indicates individual is time-invariant attributes and is controlled for in the DPD model. We predicted $\beta_{1}>0, \beta_{2}<0, \beta_{3}<0$, and $\beta_{4}<0$. $\beta_{1}$ and $\beta_{1}+\beta_{3}$ represent the association of caregiving with no SC and caregiving with SC, respectively. The ratio - $\beta_{3} / \beta_{1}$ indicates the proportion of the association between caregiving and PD moderated by SC. If the interaction term (Caregiving $\times$ SC) is not included in the regression model, the coefficient of caregiving $\left(\beta_{1}\right)$ represents the association between caregiving and SC on average for caregiving both with and without SC.

We first estimated the DPD model separately for men and women using the data over the entire wave (with the age in the range of $51-72$ years) and compared the results with those of pooled cross-sectional models. We then estimated the same DPD model for the 10-year age range group by sliding the age range by one year from 55-64 years to 63-72 years, and compared the results across nine age groups.

We employed LPM rather than logistic or probit models to predict a binary variable for PD. We did this in consideration of the general validity of LPM $[27,28]$, the straightforward interpretation of the coefficient of the interaction term [29], and a substantial reduction in our sample size due to the required exclusion of the respondents who experienced no change in a binary variable for PD over the study period from logistic fixed-

effects model regression [30].

For both descriptive and regression analyses, we compared the results between women and men. We did this because observations in previous studies provide evidence of gender differences in caregiver stressors [31-33]. For all statistical analysis, we used the Stata software package (Release 15; STATA Corp, College Station, TX, USA).

\section{Results}

\section{Descriptive analysis}

Table 1 summarizes the proportion of caregivers out of the pooled observations (individuals $\times$ waves) and examines how the prevalence of PD differed according to the combination of caregiving and SC. Of the entire sample, $12.5 \%$ of women and $8.4 \%$ of men were caring for older adults, while $72.2 \%$ of women and $68.9 \%$ of men had SC. Figure 1 compares the prevalence of PD across four combinations of caregiving and SC, based on the results reported at the bottom of Table 1. For both women and men, the prevalence of PD was higher among caregivers (6.4\% for women and $4.7 \%$ for men) than among non-caregivers (3.4\% for women and $2.8 \%$ for men). The prevalence of PD was also higher among those with no SC (6.7\% for women and $5.1 \%$ for men) than those with SC (2.6\% for women and $2.0 \%$ for men), as we expected.

Table 1

The prevalence of caregiving, social capital (SC), and psychological distress (PD) in the study sample

\begin{tabular}{|c|c|c|c|c|c|c|c|c|c|}
\hline & \multicolumn{3}{|c|}{ No caregiving } & \multicolumn{3}{|c|}{ Caregiving } & \multicolumn{3}{|l|}{ Total } \\
\hline & $\mathrm{SC}$ & No SC & Total & SC & No SC & Total & SC & No SC & Total \\
\hline \multicolumn{10}{|c|}{ Number of observations } \\
\hline Women & 107,635 & 41,930 & 149,565 & 15,755 & 5,563 & 21,318 & 123,390 & 47,493 & 170,883 \\
\hline Men & 96,796 & 44,753 & 141,549 & 9,680 & 3,375 & 13,055 & 106,476 & 48,128 & 154,604 \\
\hline Total & 204,431 & 86,683 & 291,114 & 25,435 & 8,938 & 34,373 & 229,866 & 95,621 & 325,487 \\
\hline \multicolumn{10}{|c|}{ Proportion (\%) } \\
\hline Women & $63.0 \%$ & $24.5 \%$ & $87.5 \%$ & $9.2 \%$ & $3.3 \%$ & $12.5 \%$ & $72.2 \%$ & $27.8 \%$ & $100.0 \%$ \\
\hline Men & $62.6 \%$ & $28.9 \%$ & $91.6 \%$ & $6.3 \%$ & $2.2 \%$ & $8.4 \%$ & $68.9 \%$ & $31.1 \%$ & $100.0 \%$ \\
\hline Total & $62.8 \%$ & $26.8 \%$ & $89.5 \%$ & $8.1 \%$ & $2.9 \%$ & $10.9 \%$ & $70.7 \%$ & $29.5 \%$ & $100.0 \%$ \\
\hline \multicolumn{10}{|c|}{ Prevalence of PD (\%) } \\
\hline Women & $2.4 \%$ & $6.1 \%$ & $3.4 \%$ & $4.6 \%$ & $11.5 \%$ & $6.4 \%$ & $2.6 \%$ & $6.7 \%$ & $3.8 \%$ \\
\hline Men & $1.8 \%$ & $4.9 \%$ & $2.8 \%$ & $3.3 \%$ & $8.4 \%$ & $4.7 \%$ & $2.0 \%$ & $5.1 \%$ & $3.0 \%$ \\
\hline Total & $2.1 \%$ & $5.4 \%$ & $3.1 \%$ & $4.1 \%$ & $10.3 \%$ & $5.7 \%$ & $2.3 \%$ & $5.9 \%$ & $3.4 \%$ \\
\hline
\end{tabular}

Page $4 / 11$ 
Equally important, Fig. 1 shows that, for women, the difference between caregivers with SC and non-caregivers with SC (4.6\% - $2.4 \%$ ) was somewhat smaller than the difference between caregivers who experienced PD while having no SC and non-caregivers with no SC (11.5\% $6.1 \%)$. The same was true of men (3.3\% - 1.8\% vs. $8.4 \%-4.9 \%)$. These comparisons suggest that SC has a moderating effect on the association between informal caregiving and PD. This effect can be formally confirmed by the two-way analysis of variance, which showed that caregiving, SC, and their interaction all significantly explained the variance of the probability of PD $(p<0.001$, not reported in Table 1 or Fig. 1$)$. It should be noted that the results in Table 1 and Fig. 1 were not adjusted for other factors.

\section{Regression analysis}

Table 2 summarizes the regression results using the entire study sample. This compares the estimated associations with the probability of PD between the pooled cross-sectional and DPD models. The upper part of the table presents the results obtained when we did not include the interaction term (Caregiving $\times$ SC), while the lower part presents the results with the interaction term. The full regression results are presented in Table S1 in the Supplementary file.

Table 2

Estimated association with caregivers' psychological distress (PD): pooled cross-sectional and dynamic panel data (DPD) models ${ }^{\text {a }}$

\begin{tabular}{|c|c|c|c|c|c|c|c|c|c|c|c|c|c|}
\hline & & \multicolumn{6}{|c|}{ Women } & \multicolumn{6}{|l|}{ Men } \\
\hline & & \multicolumn{3}{|c|}{ Pooled cross-sectional } & \multicolumn{3}{|l|}{ DPD } & \multicolumn{3}{|c|}{ Pooled cross-sectional } & \multicolumn{3}{|l|}{ DPD } \\
\hline & & Coef. & $95 \% \mathrm{Cl}$ & & Coef. & $95 \% \mathrm{Cl}$ & & Coef. & $95 \% \mathrm{Cl}$ & & Coef. & $95 \% \mathrm{Cl}$ & \\
\hline \multicolumn{14}{|c|}{ (1) Not including the interaction term (Caregiving $\times \mathrm{SC}$ ) } \\
\hline Caregiving & $\beta_{1}$ & 0.026 & $(0.022$ & $0.031)$ & 0.021 & (0.016, & $0.027)$ & 0.016 & $(0.012$ & $0.021)$ & 0.011 & $(0.005$ & $0.016)$ \\
\hline SC & $\beta_{2}$ & $\overline{0} .024$ & $\begin{array}{l}(- \\
0.026\end{array}$ & $\overline{0.022)}$ & $\overline{0} .007$ & $\begin{array}{l}(- \\
0.010\end{array}$ & $\overline{0.004)}$ & $\overline{0} .019$ & $\begin{array}{l}(- \\
0.021\end{array}$ & $\overline{0.017)}$ & $\overline{0} .008$ & $\begin{array}{l}(- \\
0.011\end{array}$ & $-0.005)$ \\
\hline $\begin{array}{l}\text { PD } \\
\text { (lagged) }\end{array}$ & $\beta_{4}$ & 0.422 & $(0.416$ & $0.427)$ & 0.055 & $(0.047$ & $0.064)$ & 0.379 & $(0.373$ & $0.384)$ & 0.046 & $(0.037$ & $0.056)$ \\
\hline \multicolumn{14}{|c|}{ (2) Including the interaction term (Caregiving $\times \mathrm{SC}$ ) } \\
\hline Caregiving & $\beta_{1}$ & 0.046 & $(0.037$ & $0.054)$ & 0.035 & $(0.024$ & $0.046)$ & 0.037 & $(0.028$ & $0.045)$ & 0.029 & (0.018, & $0.040)$ \\
\hline SC & $\beta_{2}$ & $\overline{0} .023$ & $\begin{array}{l}(- \\
0.025,\end{array}$ & $\overline{0} .020)$ & $\overline{0} .007$ & $\begin{array}{l}(- \\
0.010,\end{array}$ & - & $\overline{0} .018$ & $\begin{array}{l}\text { (- } \\
\text { 0.020, }\end{array}$ & $\overline{0.016)}$ & $\overline{0} .007$ & $\begin{array}{l}(- \\
0.010,\end{array}$ & $-0.004)$ \\
\hline $\begin{array}{l}\text { Caregiving } \\
\times \mathrm{SC}\end{array}$ & $\beta_{3}$ & $\overline{0} .027$ & $\begin{array}{l}(- \\
0.036\end{array}$ & $\overline{0} .017)$ & $\overline{0} .019$ & O. & $\overline{0} .006)$ & $\overline{0} .027$ & $\begin{array}{l}(- \\
0.037,\end{array}$ & $\overline{0} .018)$ & $\overline{0} .025$ & $\begin{array}{l}(- \\
0.037,\end{array}$ & $-0.012)$ \\
\hline $\begin{array}{l}\text { PD } \\
\text { (lagged) }\end{array}$ & $\beta_{4}$ & 0.422 & $(0.416$ & $0.427)$ & 0.056 & $(0.047$ & $0.065)$ & 0.379 & $(0.373$ & $0.384)$ & 0.047 & $(0.038$ & $0.056)$ \\
\hline \multicolumn{14}{|c|}{ Moderating effect of SC (\%) } \\
\hline$-\beta_{3} / \beta_{1}$ & & $57.8 \%$ & $(44.4 \%$ & $71.2 \%)$ & $53.4 \%$ & $(30.4 \%$ & $76.4 \%)$ & $75.1 \%$ & $(60.0 \%$ & $90.3 \%)$ & $84.9 \%$ & $(62.0 \%$ & $107.8 \%)$ \\
\hline$N$ & & \multicolumn{6}{|c|}{120,606 observations of 14,377 individuals } & \multicolumn{6}{|c|}{114,556 observations of 13,492 individuals } \\
\hline
\end{tabular}

As seen in the upper part of Table 2, the estimated coefficients of caregiving $\left(\beta_{1}\right)$ indicated that caregiving - regardless of with or without SC corresponded to $2.1 \%$ (95\% confidence interval [CI]: 1.6-2.7\%) and 21.1\% (95\% Cl: $0.5-1.6 \%)$ higher probability of PD for women and men, respectively. The magnitudes of associations were somewhat lower than those observed in pooled cross-sectional models, $2.6 \%$ and $1.6 \%$ among women and men, respectively. Still, they were substantial compared to the actual prevalence of PD, 3.8\% and 3.0\% among women and men, respectively, as seen in Table 1. The negative coefficients of SC $\left(\beta_{2}\right)$ indicated a negative association between SC and PD, although its magnitude was much more limited in the DPD models than in the pooled cross-sectional models.

The lower part of Table 2 shows that the estimated coefficients $\left(\beta_{3}\right)$ of the interaction term (Caregiving $\times$ SC) were negative in all models. This confirms the moderating effect of SC on the association between caregiving and PD. The proportions of the association moderated by SC were $53.4 \%$ (95\% Cl: $30.4-76.4 \%)$ and $84.9 \%$ (95\% Cl: 62.4-107.8\%) for women and men, respectively. These results were slightly lower for women and higher for men when compared to the pooled cross-sectional model results. 
Table 3 summarizes the estimated associations of the probability of PD with (i) caregiving without SC $\left(\beta_{1}\right)$, (ii) the interaction between caregiving and SC $\left(\beta_{3}\right)$, and (iii) caregiving with SC $\left(\beta_{1}+\beta_{3}\right)$, as well as the estimated proportion (\%) of the moderating effect of SC (- $\left.\beta_{3} / \beta_{1}\right)$. All of these were obtained from DPD models for nine 10-year age ranges. Figure 2 graphically illustrates how the estimated associations of PD (i) caregiving with no SC and (ii) caregiving with SC) changed according to a caregiver's age. In Table 3 and Fig. 2, we observe that for women, the association of PD with caregiving with no SC increased as a caregiver got older. Meanwhile, the association of PD with caregiving with SC declined slightly. The moderating effect of SC increased as age advanced; the proportion of the effect increased from $39.3 \%$ for women aged 55-64 years to $82.8 \%$ for those aged 62-71 years. In the case of men, the increase in the association of PD with caregiving without SC as age advanced was much more limited than for women. The association of PD with caregiving with no SC remained largely unchanged and nonsignificant over the entire age range for men. The proportion of the moderating effect of SC was somewhat larger and showed a less clear increase as age advanced compared to the results found in women.

Table 3

Estimated association with caregivers' psychological distress by age group ${ }^{a}$

\begin{tabular}{|c|c|c|c|c|c|c|c|c|c|c|c|c|}
\hline \multirow{2}{*}{$\begin{array}{l}\text { Age range } \\
\text { (years) }\end{array}$} & \multicolumn{3}{|c|}{ Caregiving with no SC } & \multicolumn{3}{|c|}{ Caregiving $\times \mathrm{SC}^{\mathrm{b}}$} & \multicolumn{3}{|c|}{ Caregiving with SC } & \multicolumn{3}{|c|}{ Moderating effect of SC } \\
\hline & $\beta_{1}$ & $95 \% \mathrm{Cl}^{\mathrm{C}}$ & & $\beta_{3}$ & $95 \% \mathrm{Cl}$ & & $\beta_{1}+\beta_{3}$ & $95 \% \mathrm{Cl}$ & & $-\beta_{3} / \beta_{1}$ & $95 \% \mathrm{Cl}$ & \\
\hline \multicolumn{13}{|l|}{ Women } \\
\hline $55-64$ & 0.031 & $(0.044$ & $0.018)$ & -0.012 & $(-0.027$ & $0.003)$ & 0.019 & (0.011, & $0.026)$ & $39.3 \%$ & $(4.7 \%$ & $73.8 \%)$ \\
\hline $56-65$ & 0.032 & $(0.045$ & $0.019)$ & -0.014 & $(-0.029$ & $0.000)$ & 0.018 & (0.010, & $0.025)$ & $44.9 \%$ & $(13.4 \%$ & $76.3 \%)$ \\
\hline $57-66$ & 0.036 & $(0.049$ & $0.023)$ & -0.017 & $(-0.032$ & $-0.003)$ & 0.018 & (0.011, & $0.025)$ & $48.9 \%$ & $(21.3 \%$ & $76.4 \%)$ \\
\hline $58-67$ & 0.037 & $(0.051$ & $0.024)$ & -0.020 & $(-0.035$ & $-0.004)$ & 0.018 & (0.010, & $0.025)$ & $52.4 \%$ & $(26.5 \%$ & $78.3 \%)$ \\
\hline $59-68$ & 0.039 & $(0.053$ & $0.025)$ & -0.020 & $(-0.036$ & $-0.005)$ & 0.019 & (0.011, & $0.026)$ & $51.7 \%$ & $(26.1 \%$ & $77.3 \%)$ \\
\hline $60-69$ & 0.048 & $(0.063$ & $0.034)$ & -0.033 & $(-0.049$ & $-0.016)$ & 0.016 & $(0.008$ & $0.024)$ & $67.6 \%$ & (48.7\%, & $86.6 \%)$ \\
\hline $61-70$ & 0.055 & $(0.070$ & $0.039)$ & -0.040 & $(-0.058$ & $-0.023)$ & 0.015 & $(0.006$ & $0.023)$ & $73.1 \%$ & (56.0\%, & $90.3 \%)$ \\
\hline $62-71$ & 0.062 & $(0.079$ & $0.045)$ & -0.051 & $(-0.070$ & $-0.032)$ & 0.011 & (0.001, & $0.020)$ & $82.8 \%$ & (67.2\%, & $98.3 \%)$ \\
\hline $63-72$ & 0.060 & $(0.079$ & $0.042)$ & -0.047 & $(-0.068$ & $-0.026)$ & 0.013 & $(0.003$ & $0.023)$ & $78.0 \%$ & $(60.1 \%$ & $96.0 \%)$ \\
\hline \multicolumn{13}{|l|}{ Men } \\
\hline $55-64$ & 0.024 & $(0.037$ & $0.011)$ & -0.020 & $(-0.035$ & $-0.005)$ & 0.004 & $(-0.004$ & $-0.012)$ & $83.4 \%$ & (50.9\%, & $116.0 \%)$ \\
\hline $56-65$ & 0.022 & $(0.034$ & $0.009)$ & -0.018 & $(-0.033$ & $-0.003)$ & 0.004 & $(-0.004$ & $-0.011)$ & $83.3 \%$ & (47.6\%, & $118.9 \%)$ \\
\hline $57-66$ & 0.019 & $(0.032$ & $0.006)$ & -0.015 & $(-0.030$ & $-0.000)$ & 0.004 & $(-0.003$ & $-0.012)$ & $76.9 \%$ & (36.6\%, & $117.3 \%)$ \\
\hline $58-67$ & 0.022 & $(0.035$ & $0.009)$ & -0.015 & $(-0.030$ & $-0.001)$ & 0.007 & $(-0.000$ & $-0.014)$ & $69.2 \%$ & (32.2\%, & $106.2 \%)$ \\
\hline $59-68$ & 0.026 & (0.039, & $0.012)$ & -0.020 & $(-0.035$ & $-0.005)$ & 0.006 & $(-0.002$ & $-0.013)$ & $78.2 \%$ & $(47.6 \%$ & $108.9 \%)$ \\
\hline $60-69$ & 0.021 & $(0.035$ & $0.008)$ & -0.016 & $(-0.031$ & $0.000)$ & 0.006 & $(-0.002$ & $-0.013)$ & $72.4 \%$ & (33.2\%, & $111.7 \%)$ \\
\hline $61-70$ & 0.028 & $(0.043$ & $0.013)$ & -0.022 & $(-0.039$ & $-0.005)$ & 0.005 & $(-0.002$ & $-0.013)$ & $80.3 \%$ & $(50.0 \%$ & $110.6 \%)$ \\
\hline $62-71$ & 0.025 & $(0.041$ & $0.009)$ & -0.020 & $(-0.038$ & $-0.002)$ & 0.005 & $(-0.003$ & $-0.014)$ & $79.7 \%$ & (43.1\%, & $116.2 \%)$ \\
\hline $63-72$ & 0.032 & $(0.050$ & $0.015)$ & -0.028 & $(-0.048$ & $-0.008)$ & 0.004 & $(-0.005$ & $-0.013)$ & $87.5 \%$ & $(57.8 \%$ & $117.1 \%)$ \\
\hline
\end{tabular}

\section{Discussion}

This study examined the extent to which SC moderated the association between caregiving to older parents or a spouse and caregiver's PD. Unlike most preceding studies, this study applied a DMD model analysis, which allowed us to control for an individual's time-invariant attributes in a dynamic framework. This approach, combined with the limitation of the sample to those who provided no care in the previous year, 
mitigated the biases that cannot be controlled for when using cross-sectional regression. In addition, we compared the results across different age groups, considering the possibility of a change in the relevance of SC for caregivers' mental health as caregivers aged. The key findings and their implications are summarized as follows:

First, the results confirmed the moderating effect of SC on the association between caregiving and PD for both women and men, a result consistent with previous studies that showed the favorable impact of SC on health [16-19]. Even after controlling for individual-specific fixed effects and other factors, the DPD model results suggest that SC mitigated a substantial portion of the adverse impact of caregiving on caregivers' mental health. This implies that socially isolated caregivers may face higher risks of deterioration in their psychological well-being, pointing to the need for policy measures to help middle-aged and older adults create and enhance their SC.

Second, the moderating effect of SC increased as caregivers aged. The adverse impact of caregiving tended to be more serious for older caregivers, especially for women. This result highlighted health problems related to the issue of "elderly-for-elderly care." It should be noted, however, that the moderating effect of SC tended to offset the enhanced adverse impact of caregiving on PD. As a result, the probability of PD for female caregivers with SC declined, albeit slightly, as age advanced. Similarly, the probability for male caregivers with SC to experience PD remained relatively low and not significantly different from that of non-caregivers. Many studies have provided evidence for the importance of SC for older adults' well-being $[16,18]$, presumably because the opportunities to participate in social activities are likely to become more limited as people age. The results of this study underscored the importance of SC for older caregivers, by showing that SC prevented an age-related increase in the adverse impact of caregiving on a caregiver's mental health.

Third, we observed a substantial difference in the moderating effect of SC. We found that the effect differed substantially between women and men. As already observed in previous studies, there are consistently higher levels of PD in women [31-33]. Notably, the proportion of the association moderated by SC $\left(-\beta_{3} / \beta_{1}\right)$ was somewhat more limited for women than for men. Considering the magnitude of the interaction effect between caregiving and SC $\left(\left|\beta_{3}\right|\right)$ was almost in the same range or even larger for women (especially for older age groups), as seen in Table 3, an SC's lower moderating effect for women can be accounted for by a closer association between caregiving and PD, that is, higher value of $\beta_{1}$, for women. This appears to have partly reflected that women undertake more intensive caregiving; indeed, the average hours for caregiving per week was 19.0 hours (SD: 23.7 hours) among female caregivers, as compared to 13.2 hours (SD: 23.7 hours) among male caregivers. Hence, the lower moderating effect of SC for women did not mean a limited importance of SC for women. In fact, that effect increased substantially as female caregivers got older, as clearly seen in Fig. 2. Meanwhile, our results showed a more limited increase in the moderating effect of SC for men as they got older. This may reflect that a man spends longer in the workplace, which was likely to reduce the chances of enhancing SC, as compared to women.

We recognize that this study has several limitations and that many issues remain to be addressed. Importantly, we did not fully address the potential endogeneity of SC. DPD model analysis controlled for the confounding effects of an individual's attributes on the associations between key variables, and we found that the estimation results differed substantially from pooled cross-sectional models, as already suggested by previous fixed-effects model studies [34,35]. However, we could not exclude the possibility that caregiving affects SC during the caregiving process [36], especially as we focused on the individual-level SC. Second, we did not examine the evolution of caregivers' PD over time. Instead, we focused on the relatively short-term association between the onset of caregiving and a caregiver's PD in order to mitigate potential simultaneity biases. Going forward, we should extend the analysis to the evolution of a caregiver's PD over time [37-39]. Examining that must involve a two-way interaction with SC, as mentioned above. In addition to these methodological limitations, caution should be exercised when generalizing the results. The relevance of caregiving and caregivers' mental health may depend heavily on formal long-term care provisions, family care norms, and other socio-cultural backgrounds [40].

\section{Conclusions}

This study confirmed the moderating effect of SC on the association between family caregiving and caregivers' PD for both women and men. The results also confirmed that this effect prevented PD from continued deterioration as age advanced, which suggests the need to keep older caregivers from becoming socially isolated.

\section{List Of Abbreviations}

Cl, confidence interval; DPD, dynamic panel data; K6, Kessler 6; LPM, linear probability model; MHLW, Ministry of Health, Labour and Welfare; $\mathrm{OR}$, odds ratio; PD, psychological distress; SC, social capital; SD, standard deviation

\section{Declarations}

Ethics approval and consent to participate

Page $7 / 11$ 
Data obtained from the Longitudinal Survey of Middle-Aged and Older Adults, a 14-wave panel survey conducted by the Japanese MHLW each year between 2005 and 2018, were used. This survey was officially approved by the Statistics Committee of the Japanese Ministry of Internal Affairs and Communications (Approval No: 26103, Statistics Code: 00450045), under the Japan's Statistics Act, which required that it be reviewed from statistical, legal, ethical, and other viewpoints. Survey data were obtained from the MHLW, with official permission. Therefore, ethical approval was not required in this study. The need for written consent was waived, in line with the Statistics Act.

\section{Consent for publication}

Not applicable.

\section{Availability of data and material}

The data that support the findings of this study are available from the MHLW, but restrictions apply to the availability of these data, which were used under license for the current study, and so are not publicly available. Data are, however, available from the authors upon reasonable request and with permission from the MHLW.

\section{Competing interests}

The authors declare no competing interests.

\section{Funding}

This study was financially supported by a grant from the Japan Society for the Promotion of Science (JSPS) (Grant Number: 20K01722). The funding body had no role in the design of the study, in the collection, analysis, and interpretation of the data, or in writing the manuscript.

\section{Authors' contributions}

The dataset was constructed by T.O., analyses were performed by T.O., and the initial manuscript was prepared by T.O. in cooperation with KS. The final manuscript was read and approved by T.O. and K.S.

\section{References}

1. Amirkhanyan AA, Wolf DA. Parent care and the stress process: findings from panel data. J Gerontol B Psychol Sci Soc Sci. 2006 Sep;61(5):S248-55. doi: 10.1093/geronb/61.5.s248.

2. Cooper C, Balamurali TBS, Livingston G. A systematic review of the prevalence and covariates of anxiety in caregivers of people with dementia. Int Psychogeriatr. 2007;19:175-95. doi: 10.1017/S1041610206004297.

3. Del-Pino-Casado R, Rodríguez Cardosa M, López-Martínez C, Orgeta V. The association between subjective caregiver burden and depressive symptoms in carers of older relatives: A systematic review and meta-analysis. PLOS ONE. 2019;14:e0217648. doi: 10.1371/journal.pone.0217648.

4. Haley WE, Roth DL, Sheehan OC, Rhodes JD, Huang J, Blinka MD, et al. Effects of transitions to family caregiving on well-being: A longitudinal population-based study. J Am Geriatr Soc. 2020;68(12):2839-46. doi: 10.1111/jgs.16778.

5. Hiel L, Beenackers MA, Renders CM, Robroek SJ, Burdorf A, Croezen S. Providing personal informal care to older European adults: should we care about the caregivers' health? Prev Med. 2015 Jan;70:64-8. doi: 10.1016/j.ypmed.2014.10.028.

6. Pinquart M, Sörensen S. Differences between caregivers and noncaregivers in psychological health and physical health: a meta-analysis. Psychol Aging. 2003;18(2):250-67. doi: 10.1037/0882-7974.18.2.250.

7. Smith GR, Williamson GM, Miller LS, Schulz R. Depression and quality of informal care: a longitudinal investigation of caregiving stressors. Psychol Aging. 2011;26;3:584-91. doi: 10.1037/a0022263.

8. Fagerström C, ElmståhI S, Wranker LS. Analyzing the situation of older family caregivers with a focus on health-related quality of life and pain: a cross-sectional cohort study. Health Qual Life Outcomes. 2020;18:79. doi: 10.1186/s12955-020-01321-3.

9. Tsai CF, Hwang WS, Lee JJ, Wang WF, Huang LC, Huang LK, et al. Predictors of caregiver burden in aged caregivers of demented older patients. BMC Geriatr. 2021;21(1):59. doi: 10.1186/s12877-021-02007-1.

10. Ninomiya S, Tabuchi K, Rahman MM, Kobayashi T. Factors associated with mental health status among older primary caregivers in Japan. Inquiry. 2019;56:46958019859810. doi: 10.1177/0046958019859810.

11. Ministry of Health, Labour and Welfare. Comprehensive Survey of Living Conditions. https://www.mhlw.go.jp/toukei/saikin/hw/k-tyosa/ktyosa19/dl/05.pdf. Accessed 30 May 2021, 2020; 2019.

12. Putnam RD. Bowling Alone: The collapse and revival of American community. New York: Simon and Schuster; 2000. 
13. Bourdieu P. The forms of capital. In: Handbook of theory and research for the sociology of education. Richardson JG, editor. New York: Greenwood Press; 1986. p. 41-58.

14. Lin N. Social Capital: a theory of social structure and action. Cambridge: Cambridge University Press; 2001.

15. Portes A. Social capital: its origins and applications in modern sociology. Annu Rev Sociol. 1998;24:1-24. doi.org/10.1146/annurev.soc.24.1.1.

16. Aida J, Kondo K, Hirai H, Subramanian SV, Murata C, Kondo N, et al. Assessing the association between all-cause mortality and multiple aspects of individual social capital among the older Japanese. BMC Public Health. 2011;11:499. doi: 10.1186/1471-2458-11-499.

17. De Silva MJ, McKenzie K, Harpham T, Huttly SR. Social capital and mental illness: a systematic review. J Epidemiol Community Health. 2005;59(8):619-27. doi: 10.1136/jech.2004.029678.

18. Ejlskov L, Mortensen RN, Overgaard C, Christensen LR, Vardinghus-Nielsen H, Kræmer SR, et al. Individual social capital and survival: a population study with 5-year follow-up. BMC Public Health. 2014;14:1025. doi: 10.1186/1471-2458-14-1025.

19. Verhaeghe PP, Tampubolon G. Individual social capital, neighbourhood deprivation, and self-rated health in England. Soc Sci Med. 2012;75:349-57. doi: 10.1016/j.socscimed.2012.02.057.

20. Mohanty I, Niyonsenga T, Cochrane T, Rickwood D. A multilevel mixed effects analysis of informal carers health in Australia: the role of community participation, social support and trust at small area level. BMC Public Health. 2020;20:1801. doi: 10.1186/s12889-020-09874-0.

21. Arellano M, Bond S. Some tests of specification for panel data: Monte Carlo evidence and an application to employment equations. Rev Econ Stud. 1991;58(2):277-97. doi: 10.2307/2297968.

22. Kessler RC, Andrews G, Colpe LJ, Hiripi E, Mroczek DK, Normand SL, et al. Short screening scales to monitor population prevalences and trends in non-specific psychological distress. Psychol Med. 2002;32(6):959-76. doi: 10.1017/s0033291702006074.

23. Kessler RC, Green JG, Gruber MJ, Sampson NA, Bromet E, Cuitan M, et al. Screening for serious mental illness in the general population with the K6 screening scale: results from the WHO World Mental Health (WMH) survey initiative. Int J Methods Psychiatr Res. 2010;19;Suppl 1:4-22. doi: 10.1002/mpr.310.

24. Furukawa TA, Kawakami N, Saitoh M, Ono Y, Nakane Y, Nakamura Y, et al. The performance of the Japanese version of the K6 and K10 in the World Mental Health Survey Japan. Int J Methods Psychiatr Res. 2008;17(3):152-8. doi: 10.1002/mpr.257.

25. Sakurai K, Nishi A, Kondo K, Yanagida K, Kawakami N. Screening performance of K6/K10 and other screening instruments for mood and anxiety disorders in Japan. Psychiatry Clin Neurosci. 2011 Aug;65(5):434-41. doi: 10.1111/j.1440-1819.2011.02236.x.

26. Organisation for Economic Co-Operation and Development. In it together: why less inequality benefits all. Paris, France: OECD; 2015.

27. Battey HS, Cox DR, Jackson MV. On the linear in probability model for binary data. R Soc Open Sci. 2019;6:190067. doi: 10.1098/rsos.190067.

28. Wooldridge JM. Introductory Econometrics: a modern approach. 5th international ed. Mason, OH: South-Western; 2013.

29. Chen JJ. Communicating complex information: the interpretation of statistical interaction in multiple logistic regression analysis. Am $J$ Public Health. 2003;93(9):1376-7; author reply 1377.

30. Baltagi BH. Econometric Analysis of Panel Data, 5th edition. Hoboken: Wiley; 2013.

31. Gallicchio L, Siddiqi N, Langenberg P, Baumgarten M. Gender differences in burden and depression among informal caregivers of demented elders in the community. Int J Geriatr Psychiatry. 2002;17(2):154-63. doi: 10.1002/gps.538.

32. Lutzky SM, Knight BG. Explaining gender differences in caregiver distress: the roles of emotional attentiveness and coping styles. Psychol Aging. 1994;9:513-9. doi: 10.1037//0882-7974.9.4.513.

33. Pinquart M, Sörensen S. Gender differences in caregiver stressors, social resources, and health: an updated meta-analysis. $J$ Gerontol $B$ Psychol Sci Soc Sci. 2006;61:P33-45. doi: 10.1093/geronb/61.1.P33.

34. Hajek A, König HH. The relation between personality, informal caregiving, life satisfaction and health-related quality of life: evidence of a longitudinal study. Qual Life Res. 2018;27(5):1249-56. doi: 10.1007/s11136-018-1787-6.

35. van den Berg B, Fiebig DG, Hall J. Well-being losses due to care-giving. J Health Econ. 2014;35(100):123-31. doi: 10.1016/j.jhealeco.2014.01.008.

36. Roth AR. Informal caregiving and social capital: a social network perspective. Res Aging. 2020;42(9-10):272-80. doi: 10.1177/0164027520912659.

37. Cameron JI, Stewart DE, Tomlinson GA, Franche RL, Hyman I, Cheung AM. Emotional distress among family caregivers in Canada: longitudinal analysis of the National Population Health Survey. Arch Public Health. 2008;66:35-45.

38. Nieboer AP, Schulz R, Matthews KA, Scheier MF, Ormel J, Lindenberg SM. Spousal caregivers' activity restriction and depression: a model for changes over time. Soc Sci Med. 1998;47(9):1361-71. doi: 10.1016/s0277-9536(98)00214-7. 
39. Oshio T. How is an informal caregiver's psychological distress associated with prolonged caregiving? Evidence from a six-wave panel survey in Japan. Qual Life Res. 2015;24(12):2907-15. doi: 10.1007/s11136-015-1041-4.

40. Verbakel E. How to understand informal caregiving patterns in Europe? The role of formal long-term care provisions and family care norms. Scand J Public Health. 2018;46(4):436-47. doi: 10.1177/1403494817726197.

\section{Figures}

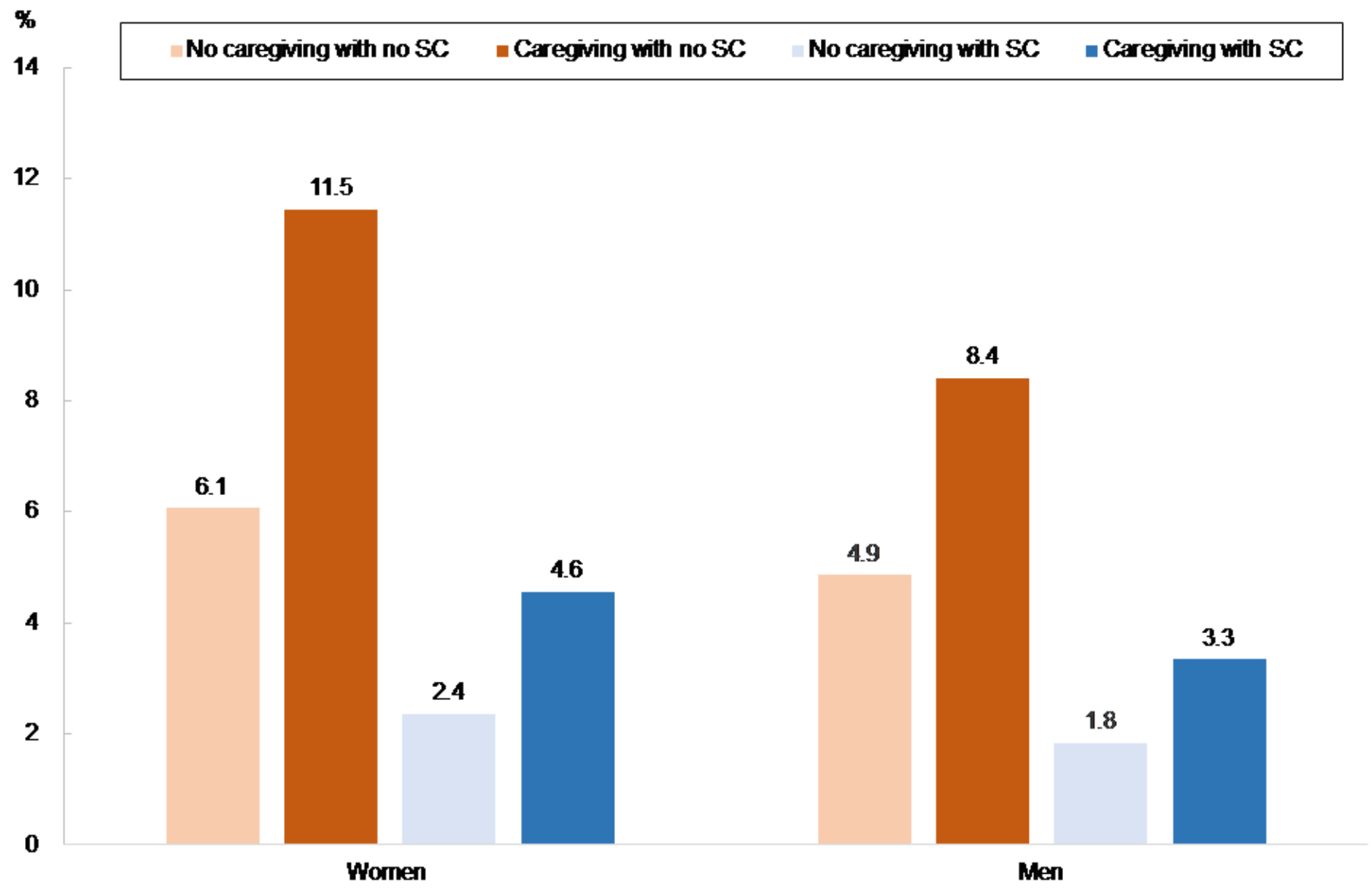

\section{Figure 1}

Prevalence of psychological distress corresponding to a combination of caregiving and social capital (SC)a a Based on the results in Table 1. 


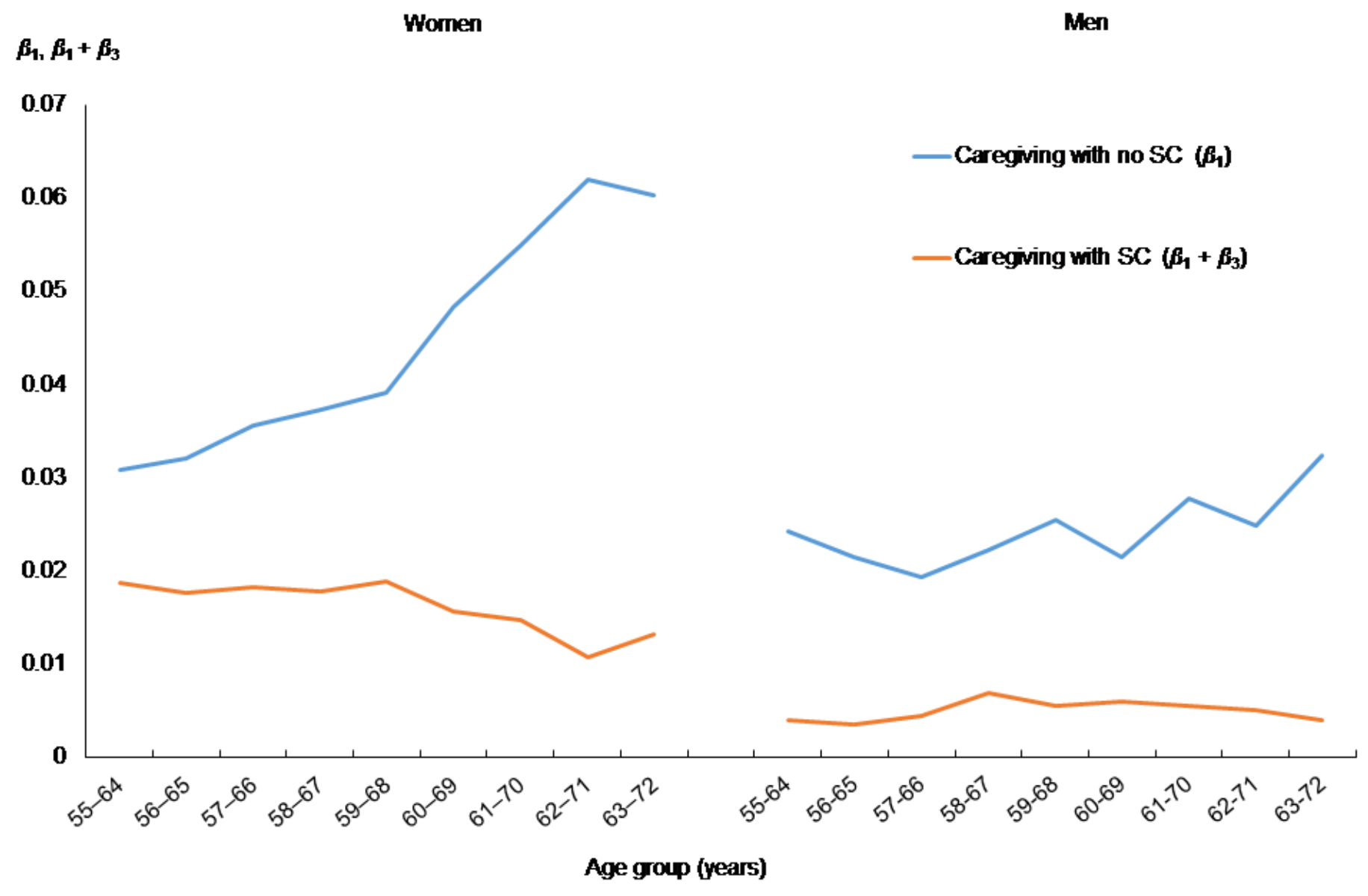

Figure 2

Estimated association of psychological distress with caregiving with/without social capital (SC) by age groupa a Based on the results in Table 3.

\section{Supplementary Files}

This is a list of supplementary files associated with this preprint. Click to download.

- Supplementaryfile20210607.docx 